\title{
Single Beat P Wave Duration
}

National Cancer Institute

\section{Source}

National Cancer Institute. Single Beat P Wave Duration. NCI Thesaurus. Code C117776.

An electrocardiographic interval measured from the onset of the $P$ wave to the offset of the $\mathrm{P}$ wave of a single beat utilizing one or more leads. (CDISC) 